\title{
Participation of community in the implementation of new rural development program in Tra Vinh province: Status and solutions
}

\author{
Minh T. N. Doan ${ }^{1 *}, \&$ De N. Nguyen ${ }^{2}$ \\ ${ }^{1}$ Mekong Delta Development Research Institute, Can Tho University, Can Tho, Vietnam \\ ${ }^{2}$ College of Rural Development, Can Tho University, Can Tho, Vietnam
}

\begin{abstract}
ARTICLE INFO
Research Paper

Received: October 04, 2018

Revised: October 26, 2018

Accepted: November 05, 2018
\end{abstract}

\section{Keywords}

New rural village development

Participation of community

\section{*Corresponding author}

Doan Thi Nguyet Minh

Email: doanthinguyetminh1983@gmail.com

\begin{abstract}
The study aimed to evaluate the current status and proposed solutions for improving the engagement of communities in development of New rural village in Tra Vinh province. The study was conducted in 3 districts of Tra Vinh province namely Tra $\mathrm{Cu}$, Tieu Can and Cang Long districts by interviewing of 405 households. Statistical descriptive analysis, factor analysis, problem tree and solution tree were used. Results showed that the levels of participation depended on the wealth of household groups (rich, medium, poor and near poor). Rich household group contributed more than other groups. Three factors were found as influencing factors to the parcipation of communitues such as (1) Culture, social situation and public services, (2) Planning, infrastructure and production organization, (3) Household status and local government, with human, social, financial and physical capital figures. Based on the analysis, two overall solution groups (internal and external driving forces) from 2 main problems (subjective and objective factors) were proposed (1) Upgrading individual household capacity and (2) Improving attractive factors of community participation.
\end{abstract}

Cited as: Doan, M. T. N., \& Nguyen, D. N. (2019). Participation of community in the implementation of new rural development program in Tra Vinh province: status and solutions. The Journal of Agriculture and Development 18(1), 9-17. 


\title{
Sự tham gia của cộng đồng trong xây dựng nông thôn mới tại Trà Vinh: Thực trạng và giải pháp
}

\author{
Đoàn Thị Nguyệt Minh ${ }^{1 *}$ \& Nguyễn Ngọc Đệ ${ }^{2}$ \\ ${ }^{1}$ Viện Nghiên Cứu Phát Triển Đồng Bằng Sông Cửu Long, Trường Đại Học Cần Thơ, Cần Thơ \\ ${ }^{2}$ Khoa Phát Triển Nông Thôn, Trường Đại Học Cần Thơ, Cần Thơ
}

THÔNG TIN BÀI BÁO

Bài báo khoa học

Ngày nhận: 04/10/2018

Ngày chỉnh sửa: 26/10/2018

Ngày chấp nhận: 05/11/2018

\section{Từ khóa}

Nông thôn mới

Sự tham gia của cộng đồng

\section{*Tác giả liên hệ}

Doan Thi Nguyet Minh

Email: doanthinguyetminh1983@gmail.com

\section{TÓM TẮT}

Nghiên cứu nhằm đánh giá thực trạng và đề xuất nhóm giải pháp tăng cường sự tham gia của người dân và cộng đồng trong xây dựng nông thôn mới tại Trà Vinh. Nghiên cứu được tiến hành tại 3 huyện Trà Cú, Tiểu Cần, Càng Long tỉnh Trà Vinh trên 405 hộ bằng phương pháp điều tra xã hội học. Sử dụng phương pháp thống kê mô tả, phân tích nhân tố khám phá, xây dựng cây vấn đề và cây giải pháp tổng thể để đề xuất giải pháp cải thiện sự tham gia. Kết quả phân tích cho thấy mức tham gia của cộng đồng tùy thuộc vào điều kiện kinh tế của nhóm hộ (khá giàu, trung bình, nghèo và cận nghèo). Hộ có điều kiện kinh tế tốt sẽ có mức tham gia tốt hơn. Có 3 nhóm yếu tố được xem là có ảnh hưởng đến sự tham gia của cộng đồng (Văn hóa xã hội - tiện ích công cộng; Quy hoạch hạ tầng phát triển tổ chức sản xuất; Đặc điểm cá nhân hộ - Chính quyền ứng với các nguồn vốn: Nhân lực, Xã hội, Tài chính, Vật chất). Trên cơ sở đó, hai nhóm giải giáp tổng thể (nội lực và tác lực) từ 2 nguyên nhân chính: chủ quan và khách quan của vấn đề được đề xuất là (1) Nâng cao năng lực tham gia cá nhân và (2) Nâng cao năng lực thu hút sự tham gia của động đồng.

\section{1. Đặt Vấn Đề}

Trong công cuộc kiến thiết tỉnh từ khi được tách ra từ tỉnh Cửu Long (12/1991) thì cộng đồng Trà Vinh đã nỗ lực tham gia dưới mọi hình thức, góp phần làm thay đổi tích cực bộ mặt nông thôn của tỉnh so với lúc mới thành lập. Thành tựu nổi bật này đã hiển hiện qua báo cáo tổng kết đánh giá thành tựu đạt được trong giai đoạn (2010 - 2015) của văn phòng điều phối nông thôn mới (NTM) Trà Vinh vừa qua với 20/85 xã đạt 19/19 tiêu chí (chiếm 23,52\%). Báo cáo đã khẳng định vai trò của cộng đồng như là chủ thể "nòng cốt" và sự tham gia của cộng đồng là nguồn huy động sức dân đóng vai trò quan trọng hơn mọi thành phần nào khác (TVSB, 2016). Cộng đồng luôn là nguồn lực tập trung sẵn có tại chỗ nhiều hứa hẹn. Năng lực cộng đồng được xem là đòn bẩy thúc đẩy động cơ tham gia hiệu quả nhất giúp Trà Vinh thành công hơn trên bước đường dựng xây tỉnh nhà phát triển bền vững. Và việc sở hữu nguồn lực cộng đồng mạnh mẽ sẽ góp phần cùng chính quyền thực hiện thành công mục tiêu cuối cùng của chương trình xây dựng nông thôn mới (XDNTM). Trà Vinh có đặc trưng về "đa thành phần" trong lĩnh vực văn hóa, xã hội: đa dân tộc (321.081 người Khmer, chiếm 31,63\% và 8.553 người Hoa chiếm $0,85 \%$ so với dân số chung của tỉnh, ngoài ra còn có dân tộc người Chăm và Ấn mặc dù số lượng rất ít); đa tôn giáo, đa tín ngưỡng. Sự khác biệt này cũng là hạn chế rất lớn trong việc huy động nguồn lực tập trung trong tham gia và có thể xem đó là "rào cản" lớn về các mặt kinh tế, văn hóa, xã hội, môi trường sinh thái con người. Tuy nhiên, nếu có một hướng đi đặc thù, khéo léo, sẽ giúp cộng đồng nhanh chóng hòa quyện trong cái chung, cái hợp nhất sẽ tạo nên một Trà Vinh với nét văn hóa mang sắc thái 
mới, chiếm giữ được vị trí về lợi thế cạnh tranh mang nhiều sắc thái "văn hóa miệt vườn" vùng đồng bằng sông nước, hơn hẳn so với các tỉnh cùng khu vực. Điều quan trọng nhất là cần tìm ra được các vấn đề còn tồn tại, các rào cản trong việc tập hợp sức mạnh của cộng đồng đa dạng đó phục vụ cho công cuộc xây dựng và phát triển nông thôn. Đó cũng là lý do để nghiên cứu: "Sự' tham gia của cộng đồng trong xây dựng nông thôn mới tại Trà Vinh: thực trạng và giải pháp" mong muốn hướng đến và cần thiết được thực hiện. Nghiên cứu này nhằm đánh giá thực chất vai trò của cộng đồng, xác định những cản trở trong tiến trình xây dựng nông thôn mới trong thời gian qua, đồng thời rút ra các bài học kinh nghiệm trong việc huy động sức mạnh của cộng đồng để đẩy nhanh tiến độ xây dựng nông thôn mới trong thời gian tới.

\section{Cơ Sở Lý Luận và Phương Pháp Nghiên Cứu}

Với tổng số quan sát mẫu trong nghiên cứu là 405 mẫu, gồm các hộ dân tham gia XDNTM, được chọn theo phương pháp lấy mẫu thuận tiện có điều kiện: (1) Dựa trên đặc điểm sinh thái vùng: (nước ngọt, lợ, mặn); (2) Dựa trên các mức độ đạt tiêu chí (TC): các mức độ mạnh (19/19), trung bình (12 - 14/19), yếu (8 - 12/19); (3) Dựa trên đặc điểm loại hình kinh tế hộ: Hộ khá/giàu (có nhà kiên cố); hộ trung bình (có phương tiện sản xuất tối thiểu, phương tiện đi lại); hộ nghèo (Danh sách theo quy định địa phương). Nghiên cứu sử dụng: Phương pháp thống kê mô tả; Các giá trị trung bình cộng, nhỏ nhất, lớn nhất, tần suất, phần trăm nhằm phân tích tương quan, so sánh giá trị trung bình (với thang đo Likert 5 bậc); Kiểm định Duncan để mô tả thực trạng tham gia toàn tiến trình XDNTM ở Trà Vinh (Doan \& Nguyen, 2017a). Trên cơ sở thực trạng tham gia cùng các yếu tố tác động mạnh đến tham gia được xác định qua thực hiện phân tích nhân tố khám phá; chạy hồi quy tương quan (Doan \& Nguyen, 2016). Ngoài ra phương pháp quan sát khoa học tổng kết kinh nghiệm thực tiễn được thực hiện (Trực tiếp: quan sát trực diện đối tượng tham gia đang diễn biến trong thực tế để thu thập thông tin trực tiếp bằng mắt thường để làm rõ bản chất khái niệm sự tham gia thuộc về "lõi", căn cơ của vấn đề từ hiểu và vận dụng vào hoạt động XDNTM được biểu hiện cùng các quy luật vận động của các đối tượng ấy; Gián tiếp: dựa trên kết quả XDNTM mà phản ánh được diễn tiến bản chất về mức ảnh hưởng quá trình tham gia cùng công cụ cây vấn đề, cây giải pháp được thực hiện).

\section{Kết Quả và Thảo Luận}

\subsection{Tổng quan về thành tựu và sự tham gia của cộng đồng trong quá trình xây dựng nông thôn mởi tại Trà Vinh giai đoạn 2010 $-2015$}

Theo Doan \& Nguyen (2017b), kết quả đạt được trong phối hợp trên tinh thần chính quyền và dân cùng tham gia dựa trên báo cáo tổng kết XDNTM của VPĐP Trà Vinh (2016) tới nay qua 05 năm XDNTM, được trình bày trong Hình 1.

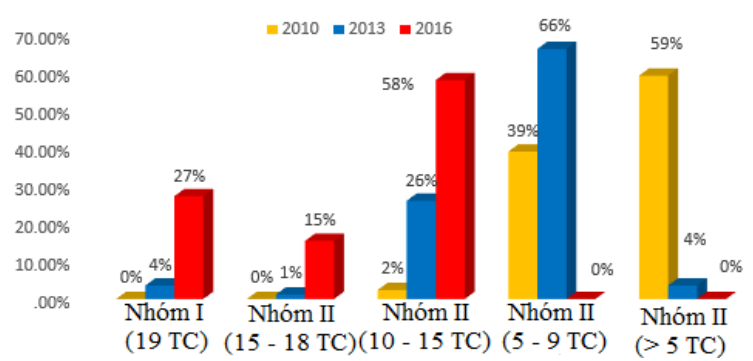

Hình 1. Kết quả thực hiện bộ tiêu chí xã nông thôn mới theo nhóm (TVSB, 2016).

Trung bình toàn tỉnh đã đạt được 13,9/19 tiêu chí xã nông thôn mới trong giai đoạn 2010 - 2015. Kết quả nghiên cứu cho thấy sự tham gia của cộng đồng trong 5 nhóm tiêu chí có sự khác nhau và mức độ tham gia cũng tùy theo khả năng tài chính của các nhóm hộ (Hình 2).

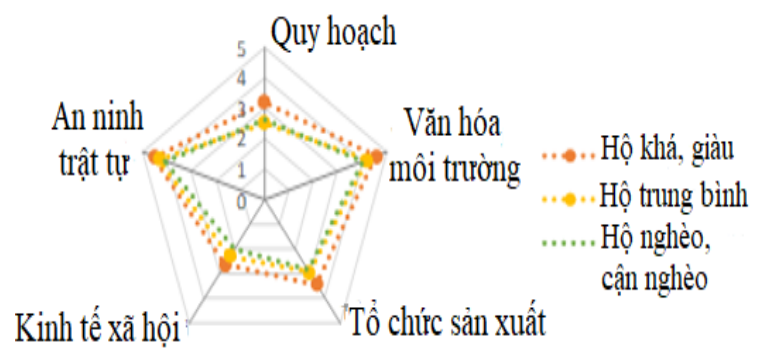

Hình 2. Mức độ tham gia của cộng đồng trong thực hiện các nhóm tiêu chí.

Mức tham gia của hộ giàu đều cao hơn hai nhóm hộ còn lại, hộ nghèo có mức tham gia thấp ở hầu hết các tiêu chí. Nếu xét về mức tham gia theo từng nhóm tiêu chí của cả 3 loại hình hộ, nhìn chung việc tham gia vào tiêu chí quy 
hoạch và các tiêu chí hạ tầng kinh tế xã hội khá thấp. Các tiêu chí về văn hóa, môi trường, tổ chức sản xuất (TCSX) và an ninh trật tự được nông hộ tham gia đóng góp nhiều hơn. Số TC đạt được ở các nhóm đều tăng nếu có sự phối hợp tốt giữa người dân và chính quyền (Doan \& Nguyen, 2017b). Hình 3 cho thấy, trong quá trình xác định hiện trạng mức điểm tham gia của hộ khá giàu là 2,69 (thang điểm 0 - 3), hộ trung bình là 2,31 và hộ nghèo cận nghèo là 1,77 . Trong công tác lập kế hoạch thực hiện cụ thể thì người dân cũng tham gia với kết quả khá tích cực (hộ khá giàu có điểm là 2,40 , hộ trung bình là 2,08 ; hộ nghèo cận nghèo là 1,38). Bước triển khai hành động, đây là công đoạn không nói mà bắt tay vào làm rồi bước cuối cùng là giám sát các quá trình thực hiện cũng tương tự, các nổ lực tham gia hộ nghèo còn yếu. Điều này cho thấy mức độ tham gia của cộng đồng trong xây dựng nong thôn mới tùy thuộc rất lớn vào điều kiện kinh tế của hộ.

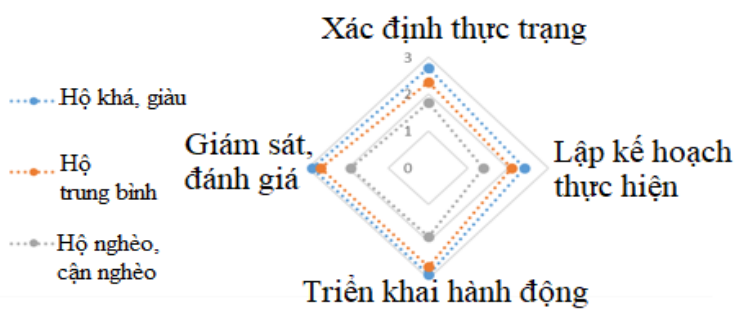

Hình 3. Mức tham gia của cộng đồng trong tiến trình xây dựng nông thôn mới tại Trà Vinh.

Như vậy, một bài học kinh nghiệm được rút ra là muốn tăng cường sự tham gia của cộng đồng thì trước hết phải cải thiện điều kiện kinh tế hộ. Ngoài ra, cần tăng cường sự hỗ trợ và hợp tác giữa các thành phần kinh tế, các cơ quan chức năng ban ngành địa phương, trong đó cộng đồng là chính. Điều này cũng được thể hiện qua khảo sát của (Doan \& Nguyen, 2017a) ở các nhóm hộ (khá/giàu, trung bình; nghèo/cận nghèo): mức tham gia dưới hình thức chia sẽ trách nhiệm được thể hiện trội hơn là hình thức ra quyết định và mức tham gia phần lớn là mức dân biết và lưu giữ thông tin nhiều hơn mức dân bàn, dân làm và dân kiểm tra. Kết quả đó cho thấy cộng đồng đã thể hiện được một phần vai trò và tìm thấy ý nghĩa của việc đóng góp tương tác cùng chính quyền mặc dù những thành quả đạt được trong giai đoạn đầu chưa cao nhưng cũng là những đóng góp đáng ghi nhận.

\subsection{Các yếu tố ảnh hưởng đến sự tham gia thực hiện xây dựng nông thôn mới tại trà Vinh}

Các nhóm yếu tố được đưa vào nghiên cứu với các biến gợi ý được xem là ảnh hưởng đến tham gia của cộng đồng được phân thành 2 nhóm: yếu tố "bên trong": đặc điểm cá nhân hộ lẫn yếu tố "bên ngoài": văn hóa, kinh tế, xã hội và môi trường. Kết quả phân tích hồi quy đa biến, các kiểm định trích từ (Doan \& Nguyen, 2016) thực hiện, thì chỉ 3 yếu tố được xem là ảnh hưởng đến sự tham gia: (1) yếu tố con người là chủ thể với đặc điểm cá nhân khác nhau cùng (2) yếu tố văn hóa xã hội $(\mathrm{VHXH}) ;(3)$ yếu tố có sở hạ tầng, quy hoạch, tồ chức sản xuất (TCSX) thực tế khác nhau đã làm ảnh hưởng đến sự tham gia. Tuy nhiên nghiên cứu lý giải tập trung về hướng tác động mạnh, trừu tượng, khó nhìn về văn hóa và tiện ích công cộng (VHXHTICC với 0,269 điểm) đã ảnh hưởng lớn đến kết quả tham gia của cộng đồng cần xem xét. Bên cạnh đó yếu tố quy hoạch, hạ tầng cơ sở (QHHTCS) và đặc điểm cá nhân hộ. Chính quyền (DDCHHO.CQ) cũng ảnh hưởng không nhỏ. Phân tích này giúp cộng đồng thấy trước viễn cảnh của nâng năng lực tích cực tham gia nghiêng về trạng thái "động" đạt lợi ích nhiều hơn thay vì chỉ là tham gia mức "tĩnh". Tóm lại nghiên cứu khẳng định tham gia thụ động có ảnh hưởng bởi yếu tố vừa chủ quan nội tại bên trong cá nhân lẫn yếu tố khách quan ngoại cảnh tác động bên ngoài.

\subsection{Phân tích nguyên nhân thực trạng tham gia thụ động của cộng đồng trong xây dựng nông thôn mới tại Trà Vinh}

\subsubsection{Nguyên nhân chủ quan}

Năng lực cứng thấp, tức trình độ học vấn, chuyên môn, nhận thức chưa cao với hệ giá trị thái độ còn tiêu cực, rập khuôn, thiếu linh hoạt, thiếu năng động biểu hiện bên ngoài với năng lực mềm chưa thành thạo, phần lớn do cả khu vực ĐBSCL không chỉ Trà Vinh với thực trạng "trọng bằng cấp" vẫn còn (Duong, 2015).

Chưa chú trọng đào tạo đạt năng lực giải quyết các vấn đề thực tiễn. Về cơ cấu thì hiệu quả, năng suất đạt được chưa tương xứng trong phân bổ thành phần nhân lực phù hợp với chuyên môn ngành nghề. Theo Vu (2015), khoảng $70 \%$ nguồn nhân lực ở nông thôn là nông dân; $30 \%$ còn lại gồm nhân lực công nhân và nhân lực chất lượng 
cao; trong đó còn bất cập lớn là sự phân bổ không hợp lý, mâu thuẫn lớn giữa lượng và chất đối với nguồn nhân lực chất lượng cao, nổi cộm với tiêu điểm "vùng trũng" vì sự phát huy của số lao động qua đào tạo chiếm phần trăm rất thấp (40\%); độ "thực chất" của bằng cấp chiếm phần trăm chưa cao dù đã qua đào tạo. Năng lực quản lý kinh tế thấp dẫn đến hiệu quả tạo thu nhập chưa cao, kinh tế hộ chậm phát triển.

Đặc biệt, với dân tộc Khmer, đa số theo Phật giáo đại thừa, nhân tố tâm linh, tín ngưỡng có ảnh hưởng rất lớn đến sinh hoạt, đời sống và thái độ ứng xử của cá nhân và cộng đồng. Quan điểm chung dễ thấy là người Khmer quan tâm đến kiếp sau hơn là hiện tại. Đây là yếu tố quan trọng cần lưu ý trong vận động sự tham gia của người dân và cộng đồng trong XDNTM. Cơ sở và các chức sắc tôn giáo cần được quan tâm đúng mức trong tuyên truyền, vận động sự tham gia của người người dân như Hình 4 đã mô tả các nguyên nhân hạn chế sự tham gia của người dân và cộng đồng trong XDNTM.

\subsubsection{Nguyên nhân khách quan}

Năng lực tạo sự tham gia của cộng dồng chưa cao thể hiện bởi:

Năng lực tổ chức quản lý của bộ máy chính quyền còn yếu kém và sử dụng nguồn lực chưa hiệu quả. Năng lực mỗi cá nhân yếu kém và bản thân cá nhân chưa khai thác sử dụng hết tiềm năng, sự liên kết giữa các cấp, ban, ngành và giữa chính quyền với người dân còn yếu, nên không tạo được sự hiệp lực thành ra sức mạnh của tập thể. Vật lực và các nguồn lực tự nhiên và xã hội chưa được khai thác tốt.

Năng lực quy hoạch (QH) hạ tầng cơ sở (HTCS) chưa thật sự dựa trên nhu cầu dân ý nên chưa đồng bộ và quản lý kém hiệu quả. Hạ tầng cơ sở phát triển có đưa kimh tế hộ tăng trưởng, mức sống người dân có tăng nhưng còn thấp, kém bền vững và còn nhiều vấn đề sinh thái môi trường.

Các yếu tố văn hóa, xã hội đặc thù như đông người dân tộc Khmer, đặc tính tâm lý ngại đổi mới, trình độ dân trí thấp, tư duy kinh tế lạc hậu, quan hệ hợp tác lõng lẽo chưa được quan tâm đúng mức. Tín ngưỡng đóng vai trò quan trọng trong đời sống, sinh hoạt, phong tục, tập quán của người dân và cộng đồng. Cúng chùa, lễ hội, thực hành tôn giáo là yếu tố không thể thiếu và bất khả xâm phạm. Người dân sẵn sàng và mạnh dạn đóng góp cho chùa, nhà thờ, nhưng lại e dè, cân nhắc khi đóng góp XDNTM.

Môi trường kinh tế chưa phát triển, sản xuất nông nghiệp là chủ yếu lại rất yếu kém, chậm phát triển, đất đai manh mún, địa hình đất giồng cát đa dạng (chân, triền và đỉnh giồng), khả năng ứng dụng khoa học kỹ thuật vào sản xuất còn hạn chế, tập quán canh tác lạc hậu. Thêm vào đó, tác động ngoại cảnh ngoài tầm kiểm soát con người bởi thời tiết, biến đổi khí hậu có những diễn biến bất thường, môi trường ô nhiễm, dịch bệnh trên cây trồng, vật nuôi đã gây trở ngại rất lớn thu nhập và đời sống của cộng đồng. Các yếu tố này cần được quan tâm trong phát triển kinh tế và đa dạng hóa sinh kế của nông hộ.

\subsection{Giải pháp đề xuất cải thiện vấn đề tham gia thụ động trong xây dựng nông thôn mới tại Trà Vinh}

Nguyen \& ctv. (2015) đã nghiên cứu và khẳng định rằng: Động cơ là một trong 5 thuộc tính cơ bản của khung lý thuyết năng lực (cư thể 5 thuộc tính này bao gồm: động cơ, đặc điểm cá nhân, vai trò xã hội, thái độ hay giá trị, kiến thức và kỹ năng) trong đó năng lực hữu hình thể hiện bên ngoài là kiến thức và kỹ năng còn năng lực vô hình là những gì được bắt nguồn từ bên trong mà bộc lộ ra bên ngoài đó là thái độ hay giá trị. Thuộc tính động cơ ở đây được định nghĩa là những điều mà một cá nhân luôn nghĩ về hay mong muốn dẫn đến tạo ra sự nhất quán trong hành động, đồng thời cũng là sự ứng xử hướng về các hành động và mục tiêu. Nên động cơ thúc đẩy cộng đồng tham gia ở mức thấp hay cao sẽ đánh giá được năng lực tham gia của cộng đồng là tích cực hay thụ động. Quan trọng là cộng đồng nhận thức được sự tham gia để sinh tồn, để chinh phục mọi nấc thang cho nhu cầu sống thúc đẩy họ tích cực và tự giác hơn trong tham gia các hoạt động vào công cuộc XDNTM, chứ không phải sự tham gia để đạt các tiêu chí trên lý thuyết mà không gắn với ý nghĩa mục tiêu cuộc đời của mỗi con người. Qua mô tả ở Hình 5 là nội dung tóm tắt các nhóm giải pháp ưu tiên nhằm tăng cường sự tham gia, đóng góp của cộng đồng trong XDNTM.

\subsubsection{Giải pháp nâng năng lực cá nhân (động lực thúc đẩy sự tham gia)}

Nâng chất lượng giáo dục đào tạo (GDĐT) chính thức để nâng năng lực cá nhân từ bên trong (tâm lực). Bắt đầu từ năng lực chung (năng lực 


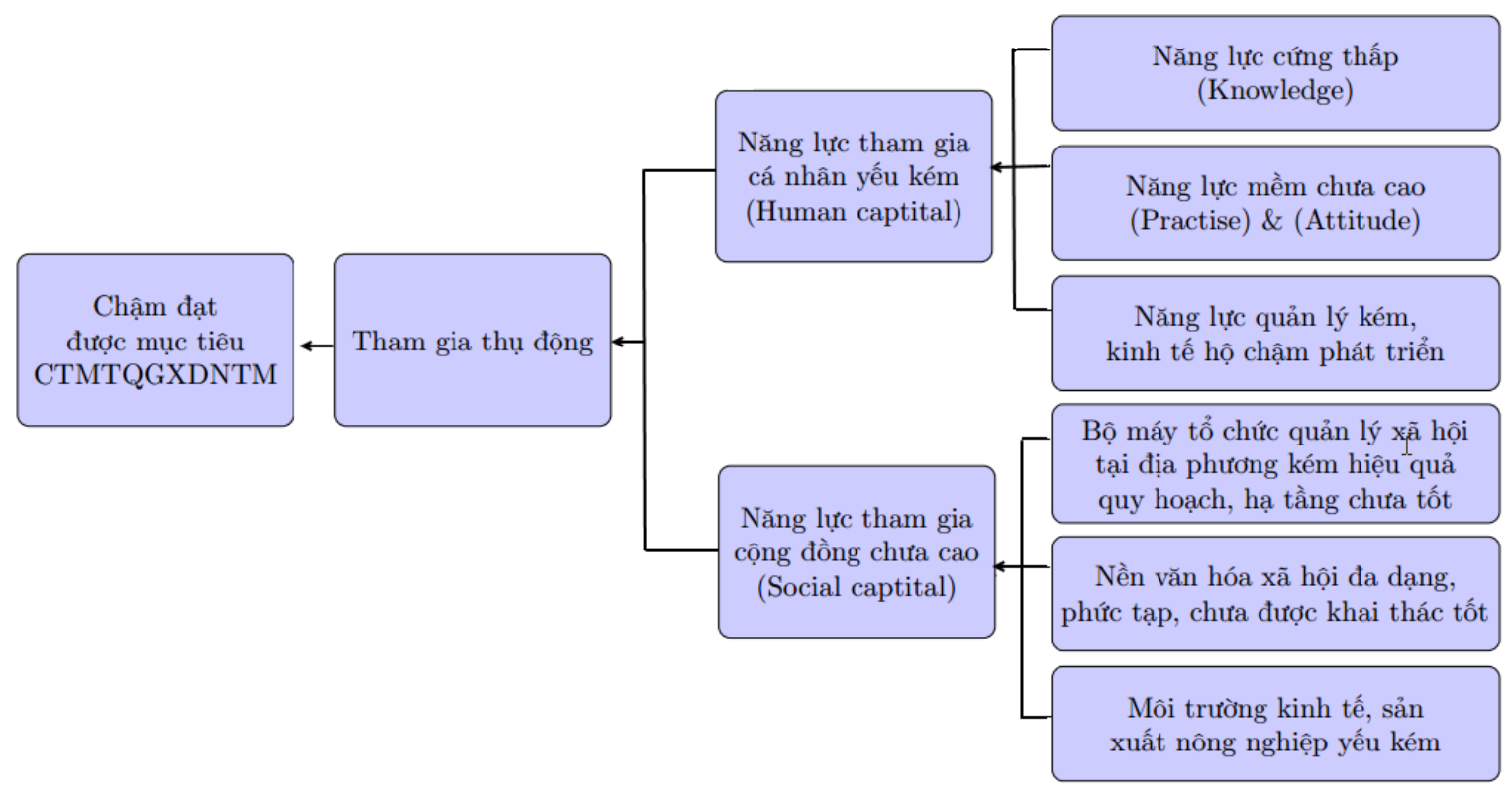

Kết quả

Nguyên nhân

Hình 4. Sơ đồ cây vấn đề hạn chế sự tham gia của cộng đồng trong xây dựng nông thôn mới.

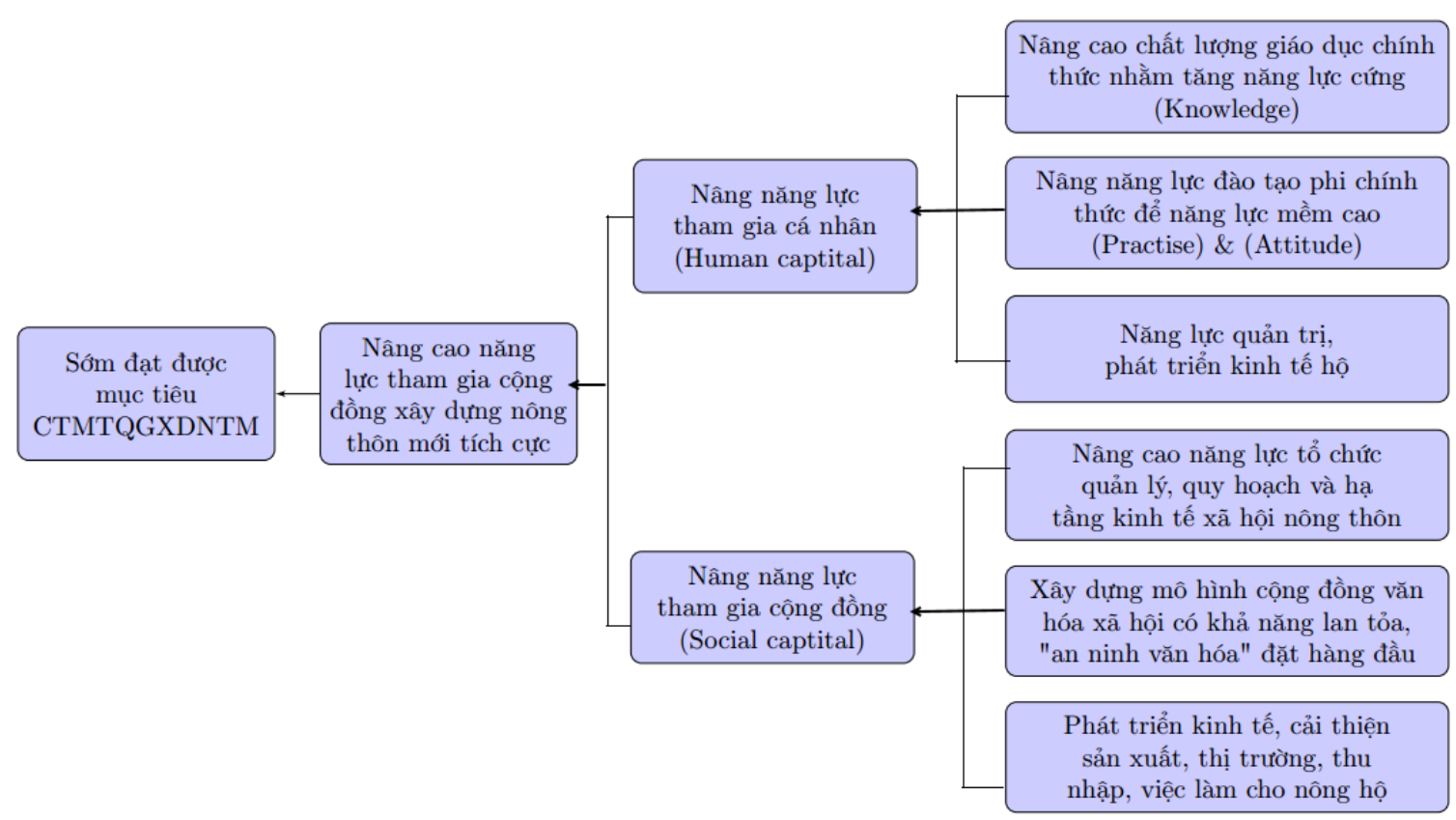

Mục tiêu

Hoạt động

Hình 5. Sơ đồ cây giải pháp nhằm tăng cường sự tham gia của cộng đồng. 
cứng) thuộc về tri thức con người, trình độ học vấn, kiến thức nền tảng, cơ bản, kiến thức chuyên môn (Knowledge) và năng lực riêng (năng lực mềm): kỹ năng (Practise), thái độ, hành vi biểu hiện đối với xã hội (Attitude).

Môi trường GDĐT chính thức được diễn ra trong trường học với các tác động tự thức bên ngoài thông qua đội ngũ thầy cô giáo chất lượng cao phục vụ các công tác GDĐT từ phương pháp giảng dạy, năng lực "truyền thự". Công cụ thiết bị hỗ trợ trực quan sinh động sẽ kích hoạt việc nâng tư duy nhận thức lên tầm mức: đam mê, tự chủ, tự giác, tự giáo dục, dới mọi hình thức của cá nhân. Song đòi hỏi cá nhân và nhà trường tạo điều kiện nhiều hơn trong ứng dụng lý thuyết vào thực tế trãi nghiệm gọi là tự đào tạo khai phóng. Phát triển nguồn nhân lực chất lượng cao thông qua việc: (1) Cải tiến yếu tố chủ quan nội tại trong công tác phát triển nguồn nhân lực có chọn lọc, có định hướng; (2) Cải tiến yếu tố khách quan trong công tác đào tạo bắt đầu từ thay đổi mục tiêu GDĐT theo hướng trọng tâm "Đức dục"; "Giáo dục nghịch cảnh" qua cơ chế chính sách giáo dục hỗ trợ triển khai cải cách phương thức tổ chức quản lý nghiêng về giáo dục trường đời. Xây dựng mô hình giáo dục theo hướng tiếp cận thực tiễn có gắn chặt chẽ giữa giáo dục nhà trường với giáo dục gia đình, đặc biệt chú trọng bố trí cán bộ giảng dạy có tâm huyết và có năng lực ở các cấp cơ sở. Cải thiện chính sách lương thưởng cho giáo viên toàn tâm, toàn lực vào công tác chuyên môn hiệu quả.

Nâng năng lực GDĐT phi chính thức (Gia đình - cộng đồng - xã hội) thông qua phương thức: (1) Giáo dục gia đình dưới hình thức noi gương từ trong gia đình lan rộng ra ngoài xã hội sẽ luôn nhắc nhở và liên tưởng có hệ thống, có lôgic và điều này dễ tác động nâng nhận thức cá nhân từ tình cảm và cách ứng xử với người thân trong gia đình đến cách hành xử trong trong cộng đồng và ngoài xã hội. Đây được xem là sự thay đổi trong bản chất con người, hướng tới một cộng đồng thân thiện được khách quan đón nhận và sẵn sàng hợp tác vì sự nghiệp chung. Hoàn thiện nhân cách đạo đức từ sự giúp đỡ của thế hệ trước thông qua thực tiễn trãi nghiệm, đúc kết thành những bài học kinh nghiệm truyền đạt tác động đến thế hệ sau góp phần thay đổi, chấn chỉnh văn hóa gia đình hòa quyện với chuẩn văn hóa cộng đồng và xã hội, tham gia hoàn thành cam kết và giữ vững các tiêu chí gia đình văn hóa trước khi đạt chuẩn ấp văn hóa rồi đến xã văn hóa, sau đó mới đến đạt chuẩn xã NTM; (2) Cần nhận thức tầm quan trọng của việc nâng các kỹ năng mềm, thông qua việc phân tích, nhận định và giải quyết các tình huống trong sinh hoạt, trong đời sống, trong mối quan hệ giữa người với người trong gia đình, cộng đồng và xã hội. Khi kỹ năng sống, vốn kinh nghiện trường đời thuần thục chắc chắn cá nhân sẽ luôn có thái độ hành xử tích cực.

Nâng cao năng lực quản trị kinh tế nhằm sử dụng tốt nhất nguồn lực nông hộ để vươn lên trong cuộc sống tinh thần và vật chất, ổn định kinh tế gia đình để có thể đóng góp cho xã hội nhiều hơn.

\subsubsection{Giải pháp nâng cao tác lực cộng đồng (động lực thu hút sự tham gia)}

Nâng cao năng lực quản lý các cấp, chính quyền cùng ban chuyên trách điều phối hoạt động XDNTM một cách linh hoạt, tránh áp đặt và có cơ chế phản hồi nghiêm túc, khách quan, theo đúng tinh thần "Dân chủ" và chủ yếu là chỉ "Do dân" và "Vì dân" đúng các cấp bậc sau: (i) "Dân biết" và "biết dân"; (ii) "Dân hiểu" và "hiểu dân"; (iii) "Dân làm" và "làm dân"; (iv) "dân nói" và "nói với dân"; (v) "Dân tin" và "tin dân"; (vi) "Dân nghe" và "nghe dân" để tiến tới (vii) "Dân phục", "Dân biểu quyết". Để đạt được điều này, bộ máy tổ chức quản lý phải hoạt động theo cách chuyên môn hóa cao. Ngoài ra, chất lượng nguồn nhân lực phục vụ công tác xây dựng NTM nhất thiết phải được nâng cao thông qua đào tạo quy hoạch bố trí cán bộ có năng lực ở cấp cơ sở, sử dụng đúng năng lực chuyên môn. Đồng thời đẩy mạnh và nâng cao chất lượng công tác tuyên truyền, vận động XDNTM cả nội dung, phương thức tổ chức với chủ đề, thông điệp ngắn gọn dễ hiểu, thuyết phục để thu hút sự đồng tình, hưởng ứng và tích cực tham gia của người dân.

Rà soát quy hoạch cho phù hợp với điều kiện sinh thái, tình hình phát triển kinh tế xã hội từng thời điểm và quan trọng là hợp với nhu cầu và lợi ích của người dân. Trên cơ sở đó, tích cực huy động mọi nguồn lực có thể để phát triển cơ sở hạ tầng phục vư phát triển kinh tế- xã hội, góp phần ổn định và nâng cao dần đời sống vật chất, tinh thần của người dân. Đây sẽ là động lực mạnh mẽ tạo sự hài lòng và đồng thuận, thúc đẩy sự tham gia tích cực hơn của người dân và cộng đồng chung tay XDNTM.

Xây dựng mô hình cộng đồng văn hóa - xã hội (CĐ VH-XH) thu hút, bền vững và có khả năng lan tỏa, lấy an ninh văn hóa làm đầu. Sự cần thiết 
và ý nghĩa của giải pháp này cũng được lý giải trên cơ sở quan điểm 2 mặt đối lập: Ánh sángbóng tối, có ánh sáng thì bóng tối sẽ tan đi. Sức mạnh tập thể quần chúng được hình thành, tạo nên hiệu ứng điều chỉnh đạo đức và hành vi cá nhân cùng động viên, giúp đỡ, hỗ trợ nhau, chung tay xây dựng đời sống vật chất, văn hóa, tinh thần ngày một tốt đẹp hơn: mô hình "Hội quán" ở tỉnh Đồng Tháp là một thí dụ. Nâng chất lượng công tác xây dựng đời sống văn hóa, công tác tư tưởng thông qua công tác tín ngướng tôn giáo hiệu quả, phát huy vai trò của các chức sắc tôn giáo tại cộng đồng. Tôn giáo, tín ngưỡng là vấn đề tâm linh, thiêng liêng của cộng đồng các dân tộc, đặc biệt với người Khmer, chiếm tỷ lệ lớn tại Trà Vinh.

Xây dựng các chương trình dự án hỗ trợ phát triển sản xuất nông nghiệp nói riêng và kinh tế nói chung, lấy tăng trưởng kinh tế hộ làm chủ lực, tái cơ cấu kinh tế, tái cấu trúc nông thôn "căn bản, toàn diện và sâu sắc" trên quan điểm "An ninh lương thực" và theo "chuỗi giá trị sản phẩm" gắn chặt với thị trường. Tổ chức lại sản xuất, xây dựng các mô hình hợp tác sản xuất, liên kết chặt chẽ với doanh nghiệp từ đầu vào đến đầu ra, gảm chi phí, nâng cao hiệu quả sử dụng vốn. Tái cơ cấu kinh tế theo hướng nâng cao thu nhập, chất lượng điều kiện sống hộ theo đa dạng sinh kế dựa trên nguồn lực sẵn có tại cộng đồng, nâng cao giá trị gia tăng đạt yếu tố bền vững trên tinh thần "công nghệ là chìa khóa then chốt trong tái cơ cấu nông nghiệp" (Nguyen \& ctv., 2016) đặc biệt chú ý trọng tâm đạt tiêu chuẩn: chất lượng nông sản, thân thiện với môi trường, an toàn trong sản xuất và tiêu thụ. Tạo điều kiện trợ giúp doanh nông khởi tạo doanh nghiệp nông nghiệp ứng dụng công nghệ cao, an toàn. Hỗ trợ sản xuất và có chiến lược sản phẩm thông qua định vị thương hiệu cho 3 mặt hàng nông sản chủ lực phù hợp điều kiện vùng sinh thái của Trà Vinh (Gạo, cây ăn trái, thủy sản). Nâng cao hiệu quả công tác khuyến nông, xây dựng và hỗ trợ nhân rộng các mô hình liên kết sản xuất tiêu thụ chặt chẽ, có trách nhiệm.

\section{Kết Luận}

Tóm lại sự tham gia của cộng đồng trong xây dựng nông thôn mới tại Trà Vinh có tính đặc thù cao: tính đa sắc tộc (Kinh, Khmer, Hoa, Chăm, Ân), đa tôn giáo (Phật giáo đại thừa (Khmer) và tiểu thừa (Kinh), Công giáo, Hồi giáo), từ đó dẫn đến đa văn hóa, phong tục tập quán. Ngoài ra, với địa hình đất giồng cát gồm chân giồng, triền giồng và đỉnh giồng xen kẽ hình thành nên tập quán sinh sống và sinh kế rất đa dạng. Hoàn cảnh gia đình, tập quán sinh sống, tôn giáo có ảnh hưởng rất lớn đến người dân và cộng đồng, xã hội phát triển, thân thiện, xoay quanh các cơ sở tôn giáo (chùa, nhà thờ, phum, sóc) và các chức sắc tôn giáo trong khu vực.

Các giải pháp trọng tâm là nâng nội lực cá nhân và cộng đồng, tạo môi trường sống lành mạnh, tiện nghi và thân thiện cả vật chất lẫn tinh thần để thu hút sự tham gia tích cực của cộng đồng trong XDNTM. Trong đó, việc nâng cao năng lực, nhận thức của cá nhân và phát triển kinh tế hộ là các giải pháp căn cơ nhất. Bên cạnh đó, việc điều chỉnh quy hoạch phù hợp với điều kiện sinh thái, tổ chức sản xuất, phát triển cơ sở hạ tầng, hỗ trợ phát triển kinh tế, kết nối thị trường và xây dựng cộng đồng văn hóa có khả năng lan tỏa..là điều kiện để phát huy năng lực cộng đồng, thay đổi nhận thức, tạo sự đồng thuận, đoàn kết, tương trợ lẫn nhau, cùng chung tay, góp sức tham gia để công tác XDNTM sớm về đích.

\section{Tài Liệu Tham Khảo (References)}

Doan, M. T. N., \& Nguyen, D. N. (2017a). Evaluation of the general results of the household participation process in new rural development program in Tra Vinh province. Journal of Agricultural Science and Technology of Nong Lam University 4, 90-98.

Doan, M. T. N., \& Nguyen, D. N. (2017b). Evaluating the real situation of new rural development program in Tra Vinh province. Journal of Agriculture and Rural Development 24, 3-11.

Doan, M. T. N. \& Nguyen, D. N. (2016). Factors affecting community participation in new rural construction in Tra Vinh province. Proceeding of Agricultural Science and New Rural Development (208-219). Can Tho, Vietnam: Can Tho University Publishing House.

Duong, T. N. (2015). Developing high quality human resources in the process of industrialization and modernization of the Mekong Delta. Proceeding of Human Resource Development for the Mekong Delta (80-95). Can Tho, Vietnam: Can Tho University Publishing House.

Nguyen, D. N., Vo, T. H., \& Nguyen, T. T. (2016). Agricultural restructuring in the Mekong Delta. In Nguyen, C. D., and Nguyen, D. N., (Eds.). Agriculture and Rural Development of the Mekong Delta Region: Achievements and Prospects (154-192). Can Tho, Vietnam: Can Tho University Publishing House.

Nguyen, T. H., Dang, N. K., Le, Van, T. T., \& Vo, D. T. (2015). Developing a capacity index for evaluation and 
proposing solutions to improve the quality of human resources in Can Tho city. Proceeding of Human Resource Development for the Mekong Delta (103-124). Can Tho, Vietnam: Can Tho University Publishing House.

TVSB (Tra Vinh Steering Board for the National Target Program on New Rural Development). (2016). Results of implementation of the national target program on the new rural development for the 2011 - 2015 period and directions, tasks for the 2016 - 2020 period. Tra Vinh, Vietnam: Coordination Office.
Vu, P. A. (2015). Status and solutions to human resource development in the Mekong Delta. Proceeding of $\mathrm{Hu}$ man Resource Development for the Mekong Delta (2027). Can Tho, Vietnam: Can Tho University Publishing House. 